\title{
MULHER-MARAVILHA E AS VIRTUDES MARAVILHOSAS
}

Carolina dos Santos Jesuino da Natividade*

Célio Juvenal Costa*

RESUMO: As histórias em quadrinhos são meios que usam as imagens junto com o texto para criar narrativas. A personagem Mulher-Maravilha foi criada para este meio em 1942, surgindo como um ícone do movimento feminista. Contudo, as lições da amazona ensinam virtudes para todos. O viver bem que suas narrativas gráficas orientam revela atitudes cujos impactos levam a benefícios individuais e coletivos. Em vários enredos há temas como justiça, compaixão, conhecimento, temperança, sabedoria, coragem, generosidade e humildade. Embora vários aspectos da personagem tenham se modificado ao longo dos seus 80 anos de existência, sua essência educadora é uma constante enriquecedora.

Palavras-chave: Histórias em quadrinhos; Mulher-Maravilha; virtudes; educação.

\section{WONDER WOMAN AND WONDER VIRTUES}

ABSTRACT: Comic books are means that combine images and text to create narratives. The Wonder Woman character was created for this type of media in 1942 and became an icon for the feminist movement, however, the Amazon warrior's lessons teach virtue to everyone. The impact caused by the righteous way of living taught in her graphic narratives can be benefited both individually and collectively. In many of her stories, subjects such as justice, compassion, knowledge, temperance, wisdom, courage, generosity and humbleness are found. Although various aspects of this character have changed over the course of its 80 years of existence, its educational essence has been a constant contributor.

Keywords: Comic books; Wonder Woman; virtues; education.

* Carolina Natividade. Mestre em psicologia pela Universidade Federal de Mato Grosso do Sul. Docente na Fundação Educacional de Jandaia do Sul- Fafijan. E-mail: carolina.s.j.natividade@gmail.com

Orcid: https://orcid.org/0000-0003-0128-8328

** Célio Juvenal Costa. Doutor em Educação pela Universidade Metodista de Piracicaba. Docente na Universidade Estadual de Maringá- UEM. E-mail: celiojuvenalcosta@gmail.com Orcid: https://orcid.org/0000-0003-1226-7805 
A Mulher-Maravilha é um dos mais famosos personagens criados para as histórias em quadrinhos (HQs), sendo uma personagem muito longeva. A princesa amazona surgiu como um ícone do feminismo, contudo suas lições e exemplos não se restringem a difundir o ideal feminista, mas a educar as pessoas sobre valores profundos que tornam a vida do indivíduo e da comunidade melhor. Este artigo visa destacar que as histórias em quadrinhos são formas de arte cujo impacto vai muito além do lazer e diversão, pois os quadrinhos podem incentivar que se tenha uma vida plena imbuída de crenças sobre ações pautadas no bem comum.

Contam-se, na atualidade, onze tipos de arte, ocupando a nona posição as histórias em quadrinhos. A expressão artística é veementemente ressaltada por Jaeger (2001, p. 63) como breve síntese e ao mesmo tempo alavanca para mutação de uma cultura. Ele explicita a função mobilizadora da arte, posto que: “[...] os valores mais elevados ganham, em geral, por meio da expressão artística, significado permanente e força emocional capaz de mover homens. A arte tem um poder ilimitado de conversão espiritual". $\mathrm{Na}$ arte, há muitos tipos de narrações. Nas mais diversas culturas, as narrações uniam, entretinham e educavam as pessoas. $\mathrm{Na}$ atualidade as histórias em quadrinhos são uma forma de contar aventuras de heróis a indicar como viver bem, dando exemplo de valores a serem seguidos. O contar histórias, como um bem cultural, tem sua relevância ressaltada por Eisner (2005, p.11):

O ato de contar histórias está enraizado no comportamento social dos grupos humanos - antigos e modernos. As Histórias são usadas para ensinar o comportamento dentro da comunidade, discutir morais e valores, ou para satisfazer curiosidades. Elas dramatizam relações sociais e os problemas de convívio, propaga ideias ou extravasa fantasias. Antigamente, o contador de histórias de um clã ou uma tribo servia como anfitrião, professor e historiador. Contar histórias preservava o conhecimento passando-o de uma geração para outra. Essa missão continuou até os tempos modernos. O narrador tem, primeiro, que ter algo a dizer, e, então, ser capaz de manusear as ferramentas para relatar. (EISNER, 2005, p. 11).

As histórias em quadrinhos executam hoje a função de narrativas gráficas, desvelando temas de interesse de muitas gerações, exercendo papel em sua educação. Weschenfelder (2011) revela que próximo de 1895 surgiam as primeiras histórias em quadrinhos nos EUA. Quanto ao valor atribuído às HQs, Weschenfelder (2011, p. 20) aponta: “Mas mesmo com todo esse tempo de existência as HQ's continuam sendo subestimadas e discriminadas nos meios acadêmicos como uma literatura marginal e sem qualidade." Apesar de pouco explorado em meio acadêmico, afigura-se em Xavier (2005) que as histórias em quadrinhos exerceram sempre grande fascínio tanto para o público infanto-juvenil quanto adulto. Desde que os quadrinhos se tornaram um produto industrializado de comunicação de massa, no início da década de 1920, nos EUA, seu poder de penetração e comunicação se tornou cada vez mais acessível ao público. 
Tradicionalmente as HQs se popularizaram com as tiras de jornal. O surgimento dos quadrinhos de ação também possibilitou a sua migração desse ambiente para um novo formato, a revista de quadrinhos, o comic book. Tal migração deu-se propriamente na década de 30. Com o sucesso da vendas de quadrinhos, possibilitou-se o surgimento de editoras voltadas exclusivamente ao segmento (BALLMANN, 2009). Conforme especifica o autor, "consagrada a forma, tanto os quadrinhos quanto seus criadores viviam atrelados às amarras oriundas do meio em que nasceram: os jornais. Primeiramente inscritas no espaço do suplemento dominical, pouco a pouco os quadrinhos migraram para o formato “tira", strip, em inglês" (BALLMANN, 2009, p. 43).

Embora as técnicas de produção de um gibi tenham evoluído muito desde as primeiras publicações, a relação estabelecida entre o leitor e a obra ainda é a mesma: extremamente visual. O que há em comum entre os quadrinhos e a literatura é o objetivo de provocar reações no leitor por um meio puramente visual, ou seja, provocar estímulos aos cinco sentidos dependendo apenas de um (BALLMANN, 2009). "Na verdade, a leitura visual é uma das habilidades obrigatórias para a comunicação neste século. E as histórias em quadrinhos estão no centro desse fenômeno.” (EISNER, 2005, p. 7). Como especifica Eisner (2005, p.19) sobre a grande dependência da imagem desse meio:

Nos quadrinhos, as imagens são, geralmente, impressionistas. Normalmente, elas são representadas de maneira simplista com o intuito de facilitar sua utilidade como linguagem. Como a experiência precede a análise, o processo digestivo intelectual é acelerado pela imagem fornecida pelos quadrinhos. (EISNER, 2005, p.19).

Com a emergência da $2^{a}$ Guerra Mundial e o papel dos Estados Unidos nessa, amplia-se a inserção do caráter político nos quadrinhos, com o mundo dos super-heróis ganhando função propagandística de determinados valores hegemônicos na sociedade (VIANA, 2005). Sobre os quadrinhos na $2^{\mathrm{a}}$ Guerra, Weschenfelder (2011, p. 36) assegura que:

Mas foi em plena Segunda Guerra Mundial, que havia a necessidade de promover a união dos cidadãos e convencer as pessoas que o conflito é necessário. E foi neste período que muitos super-heróis nasceram para combater o nazismo em suas páginas. Os países envolvidos na guerra fizeram uso massivo dos meios de comunicação para suas propagandas ideológicas, no sentido de convencer os cidadãos de que o inimigo era injusto e terrível e que as forças militares próprias tinham o dever de vencê-lo. Particularmente dos EUA, os quadrinhos dos super-heróis foram utilizados para essa finalidade. (WESCHENFELDER, 2011, p. 36).

O lado propagandista das revistas em quadrinhos na $2^{\mathrm{a}}$ Guerra Mundial no governo estadunidense é confirmado por Ballmann (2009, p. 67-68), para quem: “As capas estampavam os heróis junto com os soldados, esmurrando Hitler e Mussolini. O governo americano comprava 68 centenas de revistas para enviar ao front, na expectativa de aumentar o moral das tropas." 
Para definir mais precisamente histórias em quadrinhos, de acordo com Dumont e Ramos (2018, p. 10): “[...] Eisner (1999) cunhou o termo arte sequencial, ressaltando a capacidade de narrar fatos e acontecimentos através da combinação de palavras e imagens, retratadas de forma justaposta e em sequência deliberada.” De acordo com Eisner (2005, p.9), “[...] os conceitos complexos tornam-se mais facilmente digeríveis quando são reduzidos a imagens." $O$ formato da narração nas histórias em quadrinhos é informado por Ballmann (2009, p. 117):

Chamar os quadrinhos de "arte-sequencial" é justamente eleger a sequência como o coração desta forma de arte. Por sequência entendemos a sucessão de requadros narrativos, encadeados de uma forma tal que possibilitem a compreensão, por parte do leitor, da trama que se está narrando. (BALLMANN, 2009, p. 117).

A Nona arte possui méritos que não podem ser comparados a nenhuma outra modalidade de expressão artística; mesmo que seja influenciada e possua elementos de outras artes e mídias, ela faz uma síntese muito própria destas influências e elementos que a tornam singular (XAVIER, 2005). As revistas em quadrinhos não são nem literatura nem pintura, são combinação entre palavras e imagens. Essa combinação leva a ter características próprias, com a proporção entre imagens e palavras diferindo conforme a obra e autor (BALLMANN, 2009). Devido aos quadrinhos envolverem palavras e imagens, Ballmann (2009, p. 118) manifesta que: "Cada uma destas combinações, em maior ou menor grau, exige a participação do leitor para que ele monte, descubra o significado e participe do processo de criação da história." E o alcance dessa arte tende a se ampliar com as novas manifestações em meios que não são o papel, tais como os chamados web comics, quadrinhos feitos por e para internautas. (BALLMANN, 2009).

Um elemento muito conhecido que marca a presença dos quadrinhos em muitas regiões do planeta é o super-herói. Existem vários formatos de HQs, nem todos são histórias de heróis com superpoderes, contudo essa é sua faceta mais característica. Uma relação entre modelos míticos, heróis e os dos quadrinhos é feita por Carvalho (2006, p. 46-47), no qual encontramos que:

Toda história em quadrinhos trabalha com modelos míticos, isto é (de maneira simplificada), com personagens que representam ideias e valores que nos ajudam a entender $e$ enfrentar o mundo por meio de suas aventuras. Na maioria dos quadrinhos, esses modelos aparecem na forma de heróis, ou seja, personagens que, mais do que se destacarem por seus feitos, representam valores vigentes, têm a capacidade de satisfazer à necessidade (ou às necessidades) de seu público, encarnam os valores que simbolizam (CARVALHO, 2006, p. 46-47, sem grifos no original).

Para Weschenfelder (2011) os super-heróis estimulam nas crianças virtudes, como a coragem por vencer os medos, proteger os mais fracos e defender ideais. Eles representam os atributos que os humanos mais admiram em si próprios. São mais que apenas ídolos, são modelos morais. Dumont e Ramos (2018) defendem que não são apenas os trajes coloridos, os poderes sobre-humanos e a luta do 
bem versus o mal os motivos pelos quais os leitores de quadrinhos de super-heróis fazem a opção por essa leitura. Para os autores, as HQs de super-heróis só surtem efeito sobre os leitores na fase adulta de suas vidas devido à necessidade no ser humano de ficcionalizar sua existência. Corroborando com essa ideia, temos Ballmann (2009, p. 60), para quem:

É forçoso dizer que o gênero de super-heróis, para a história dos quadrinhos, ocupa um capítulo à parte. Pode-se afirmar que esta é sua faceta mais conhecida, mais divulgada e mais rentável. A atual avalanche de adaptações dos heróis de quadrinhos para o cinema serve de termômetro para o alcance do conceito. (BALLMANN, 2009, p. 60).

As paixões suscitadas pelas personagens dos quadrinhos chegam a ser comparadas com o devotamento religioso, como apontado por Ballmann (2009, p.61):

Os heróis gregos, por exemplo, eram descendentes de deuses e, como tais, representantes da religião partilhada pelos expectadores de suas aventuras. Embora as narrativas heroicas não se prestassem à doutrinação e catequese na mesma medida que seus correlatos cristãos, por exemplo, elas eram inegavelmente uma narrativa religiosa. Os quadrinhos, teoricamente, não possuem essa carga cultural, dispondo apenas do aspecto de entretenimento. Entretanto, existem semelhanças com o contexto religioso. Isso pode ser observado no fato de muitos aficcionados, especialmente no meio superheroístico, tratarem suas revistas e personagens favoritos com devoção quase religiosa. Convenções sobre quadrinhos atraem milhares de visitantes, mais ou menos extremados, a ponto de virem travestidos na personagem com quem mais se identificam. São os chamados cosplays, uma contração da expressão costume play, que poderia ser traduzida como "brincadeira com uniforme". (BALLMANN, 2009, p. 61).

Knowles (2008) detalha os comportamentos mais típicos de fãs de super-heróis e especifica o momento histórico em que tais comportamentos de adoração só eram vistos no campo religioso:

Hoje os super-heróis representam para nós o papel antes representado pelos deuses nas sociedades do passado. Hoje, os fãs não rezam para o Super-Homem ou para o Batman - ou pelo menos não admitem isso. Mas, quando vê fãs vestidos como seus heróis prediletos em convenções de histórias em quadrinhos, você está testemunhando o mesmo tipo de adoração que havia no mundo antigo pagão, onde os celebrantes se vestiam como o objeto de sua adoração e encenavam seus dramas em festivais e cerimônias. (KNOWLES, 2008, p. 36).

Sobre as aproximações entre o ensino das virtudes e as HQs, Weschenfelder, Fradkin e Yunes (2017, p. 1) relatam que:

Entretanto, essas HQs não são tão inocentes como aparentam, pois levam mais do que entretenimento ao leitor. Além de diversão, essas histórias introduzem e abordam de forma vívida algumas questões de suma importância enfrentadas no cotidiano de pessoas "comuns". São temas ligados à superação de adversidades, construção de identidade pessoal, elementos de ética, moral, justiça, enfrentamento de medos, de situações de violência, entre outros. (WESCHENFELDER; FRADKIN; YUNES, 2017, p. 1, sem grifos no original). 
Marny (1970), em sua análise sociológica das histórias em quadrinhos, avalia que, com os heróis, observa-se a cristalização de necessidades e tendências de uma época. Sobre as personagens poderosas das histórias em quadrinhos, Coelho (1985, p. 201-202) atesta que:

Por outro lado, não podemos esquecer que heróis ou super-heróis, dramáticos ou cômicos, heroicos ou desvalidos... são literatura antes de serem quadrinhos. Isto é, são representação simbólica de experiências humanas, essenciais; e nisso estará, com certeza, o ponto comum que os faz ser amados em qualquer ponto do globo, independente das semelhanças ou diferenças de contextos sociais, econômicos ou políticos (COELHO, 1985, p. 201-202, grifos no original).

Coelho (1985, p.207) destaca que “[...] a literatura em quadrinhos afeta inúmeras áreas: desde a literária até a ética." As histórias em quadrinhos são uma forma de arte popular e que facilmente transita entre diferentes gerações e classes sociais. As reflexões de Postema (2018) a respeito das histórias em quadrinhos remetem-nos às suas origens em uma longa tradição de textos ilustrados e sequências de narrativas visuais. $\mathrm{O}$ autor conceitua as histórias em quadrinhos como arte e narrativa que formam um sistema em que elementos díspares trabalham unidos para criar um todo complexo. As histórias em quadrinhos transmitem ideologia, com elas os leitores podem construir conhecimento sobre outros aspectos da vida social. Oferecem oportunidades para as crianças aprenderem, informalmente, sobre aspectos do mundo social (ALVES, 2001). Outro aspecto educativo das HQs é destacado por Caruso e Silveira (2009, p. 218): “O principal deles é ver como a mistura de ciência e quadrinhos pode contribuir para a construção da cidadania dos jovens [...]”.

A respeito das revistas em quadrinhos transmitirem conhecimentos e possibilitarem reflexões a partir de histórias fantásticas, com seres mitológicos ou não, Coelho (1985, p. 200) esclarece sobre a literatura em quadrinhos no Brasil: "É na década de 40 que, entre nós, se dá a verdadeira expansão da literatura quadrinizada, com seus super-heróis; séries detetivescas e aventuras que resultavam da fusão entre o maravilhoso e a ciência." Os quadrinhos expõem novos modos sociais, valores e conteúdos científicos, buscando renovar-se ciclicamente para melhor explorar objetivos comerciais.

As histórias em quadrinhos mais duradouras são capazes de mostrar a sociedade em vários momentos históricos, com seus conflitos internos diante de novas demandas sociais. As histórias da Mulher-Maravilha ao longo das décadas indicam a mudança social do papel da mulher na sociedade ocidental, principalmente após a $2^{\text {a }}$ Guerra Mundial. Diferentes uniformes, roupas de disfarce como civil, cabelos e armas utilizadas e, especialmente, comportamentos e atitudes emitidos pela primeira grande heroína demonstram transformações no papel social da mulher ao longo século XX e XXI. A relevância das HQs para estampar as mudanças sociais é defendida por Weschenfelder (2011, p. 12-13), para quem:

As HQ's tornaram-se uma referência na formação de opiniões porque de maneira sutil e perspicaz colocam em debate as questões fundamentais das relações sociais e os 
dilemas morais com os quais todos os seres humanos normais se defrontam no dia a dia. Elas abordam, na forma exemplar de vivência do personagem, as questões de suma importância enfrentadas pelos seres humanos, tais como a responsabilidade pessoal e social, a identidade pessoal, a diferença; as questões atinentes à alma, à mente e às emoções humanas, além de problemas bem concretos do cotidiano (WESCHENFELDER, 2011, p. 12-13).

Assim, tal como Eisner (2005, p. 8) assinala, "[A]utobiografias, protestos sociais, relacionamentos humanos e fatos históricos foram alguns dos temas que passaram a ser abraçados pelas histórias em quadrinhos." Por tratar de temas cotidianos, as histórias em quadrinhos dão suporte material e emocional para ensinar valores.

\section{O surgimento da Mulher-Maravilha}

Durante e logo após a $2^{\text {a }}$ Guerra Mundial, especialmente nos Estados Unidos, encarnaram mitos a valorizar o heroísmo. Se na mitologia grega havia muitos heróis do gênero masculino, o clima propício ao debate do papel na vida pública, na década de 1940, proporcionou condições ao psicólogo estadunidense Willian Moulton Marston criar uma personagem para os quadrinhos inspirada no mito das guerreiras amazonas. Na atualização do mito das amazonas, a princesa Diana deixa a Ilha Themyscera onde vivia em comunidade pacífica para ajudar o espião Steve Trevor no mundo dos homens. A MulherMaravilha é a habitante de Themyscera mais impressionante, com super força e capacidade de voar que só descobre em suas aventuras longe de sua terra natal. Desde a década de 1940 até a atualidade, a MulherMaravilha é sinônimo de virtudes como a justiça, compaixão, conhecimento, temperança, sabedoria, coragem, generosidade e humildade. A partir desse ponto, as principais virtudes expressas pela MulherMaravilha serão analisadas.

A principal virtude encarnada pela Mulher-Maravilha é a busca pela justiça, que pode ser entendida como a busca pelo que é correto para todos. Essa virtude está relacionada à cidadania, à dignidade e à liderança. A cidadania pode ser compreendida como a conexão e com o compromisso com o bem comum, tanto em sentido mais simples, como cuidar do próprio grupo, quanto em sentido mais amplo, como preocupar-se com todos em qualquer lugar (LANGLEY, 2018a). Ao tratar da virtude da justiça, Comte-Sponville (2009, p. 94) explica que uma pessoa justa "é alguém que põe sua força a serviço do direito, e dos direitos [...]”. Ainda, para esse autor, ser justo é:

[...] no sentido moral do termo, [...] recusar-se a se colocar acima das leis (pelo que a justiça, mesmo como virtude, permanece ligada à igualdade). O que significa isso, senão que a justiça é essa virtude pela qual cada um tende a superar a tentação inversa, que consiste em se colocar acima de tudo e se sacrificar a tudo, por conseguinte a seus desejos ou a seus interesses? (COMTE-SPONVILLE, 2009, p. 82). 
O justo é quem não viola a lei nem os interesses legítimos de outros. Diz Comte-Sponville (2009) que a justiça favorece a coexistência de todas as virtudes e é exigida para que exista a felicidade. Um nível amplo de cidadania, componente da justiça, é demonstrado pela amazona Diana ao deixar seu reino sem saber se conseguiria voltar, para ajudar a toda a humanidade flagelada pela $2^{a}$ Guerra (LANGLEY, 2018a). Outro aspecto relacionado à justiça é a liderança, exercida pela Mulher-Maravilha em vários momentos na "Liga da Justiça", como aponta Langley (2018a):

Embora a Mulher-Maravilha da Era de Ouro a princípio comece a integrar a Liga da Justiça (os maiores heróis da Terra 2) ${ }^{1}$ como secretária do grupo durante a Segunda Guerra Mundial, ela se mostra uma líder forte e sensata em várias das aventuras da liga. De 1960 ao início dos anos de 1980, a Liga da Justiça (os maiores heróis da Terra 1) mantém um esquema rotativo na presidência: em vez de ter um líder fixo, um novo membro assume a cadeira da liderança a cada reunião mensal, atribuindo tarefas individuais que deverão ser executadas pelos integrantes durante as missões desse respectivo mês. A Mulher- Maravilha, a única mulher que compõe a equipe nas primeiras histórias publicadas, desde o princípio participa do revezamento de liderança com outros membros (LANGLEY, 2018a, p. 72).

Outra virtude muito demonstrada por Diana é a busca pela sabedoria e conhecimento. Conforme Wood (2018a), os psicólogos positivos decompõem essa virtude nas seguintes forças: criatividade, curiosidade, mente aberta, paixão pelo conhecimento e perspectiva. Para Wood (2018a):

O jeito aberto de pensar da Mulher-Maravilha fica muito claro na sua jornada rumo ao Estados Unidos. Embora tenha vindo de um lugar isolado, rapidamente a super-heroína se envolve com a nova cultura. Diana aprende uma língua nova, um jeito diferente de se vestir, bem como as preocupações de um mundo maior. Em vez de fugir de volta para a vida que sempre teve, ela procura entender o funcionamento do seu novo mundo e empenha-se por descobrir o que deve fazer para melhorá-lo (WOOD, 2018a, p. 106).

Outro momento, em uma história narrada em 2009, em que a Mulher-Maravilha demonstra sabedoria é quando uma criatura terrível criada pelos deuses ataca a ilha Themyscera, após muita luta entre as amazonas e a criatura do mar, a princesa amazona demonstra possuir esperteza além de força física [situar melhor essa passagem. Ela se refere a qual história, exatamente?]. Mesmo com vários ossos quebrados e mãos profundamente queimadas pelo seu laço mágico usado contra ela em outra batalha, a heroína pede para que uma general amarre o laço mágico em suas mãos enfaixadas e sai do aposento onde descansava para lutar por Themyscera. Enquanto as amazonas lutavam contra as feras do mar que as atacavam, Diana se aproxima delas, reconhecendo sua força colossal. Sabendo que as feras do tempo do Craque [?] atacam tudo que as incomodam, a Mulher-Maravilha as amarra juntas para que se matem. A estratégia funciona e Ares [?], que tentava invadir a ilha, manda seu exército recuar (WONDER 
WOMAN, 33, 2009). Em outro enredo, quando a Mulher-Maravilha é acorrentada pelos homens marcianos ela observa a situação para planejar seus próximos passos².

Outro aspecto que pode ser considerado fundamental para a virtude da sabedoria é o autoconhecimento. Vemos o capital espiritual de autoconhecimento demonstrado pela amazona no episódio em que uma cidade estava em caos, com todos os habitantes brigando. A Mulher-Maravilha descobre ser uma garota com poderes designada Devastação a causa das discórdias. A princesa guerreira tentou afastá-la dos humanos, contudo foi atingida por um raio da personagem maligna, desmaiando. Em um sono profundo, lembrou de uma memória de sua infância, em seu treinamento com a general amazona Phillipus. Na época aprendeu que o excesso de confiança poderia ser um ponto fraco, pois ficava desatenta em batalha. Ao despertar, usou esse mesmo ponto fraco da Devastação. Quando a vilã atira outro raio na heroína, pensando ela estar desmaiada ainda, a Mulher-Maravilha refletiu o raio com seus braceletes, vencendo a rival. (WONDER WOMAN: as aventuras da super-heroína. Ciranda Cultural, 2018).

A Mulher-Maravilha também é exemplo da virtude de compaixão. Compaixão é participar do sentimento do outro. Essa virtude permite compartilhar do sofrimento do outro sem necessariamente aprová-lo ou concordar com suas razões, tal qual a Mulher-Maravilha muitas vezes faz para com seus inimigos. A compaixão é um amor em baixa escala, que simpatiza universalmente com tudo que sofre (COMTE-SPONVILLE, 2009). Na história em que narra como sua arquirrival Mulher-Leopardo adquiriu superpoderes e intensificou suas características más, a Mulher-Maravilha sente responsabilidade pelo ocorrido, mesmo que as inclinações ambiciosas da então amiga a tenham colocado em posição de receber a maldição da "Chita” (WONDER WOMAN, n. 6, 2019). Outra inimiga que recebe compaixão não era conhecida da Mulher-Maravilha. Ela aparece na edição de Wonder Woman (2009 nº 32), como uma monstra extremamente forte criada pelos deuses com o intuito de destruir a amazona. Mesmo após ameaçar vários de seus amigos, em meio à raiva pela inimiga e cogitar deixá-la morrer, ela age com compaixão tentando salvá-la.

Interessante esclarecimento entre o que é a piedade e a compaixão, que às vezes são confundidas, é dada por Comte-Sponville (2009, p. 127), para quem: “A piedade é sentida de cima para baixo. A compaixão, ao contrário, é um sentimento horizontal, só tem sentido entre iguais [...]”. É típico a pessoa piedosa se tomar em algum aspecto superior ao ser que suscita piedade. A horizontalidade do sentimento de compaixão demonstra uma relação mais próxima entre quem sofre e quem se compadece, pois não há compaixão sem respeito pela pessoa e sua situação. Esboçada a virtude da compaixão, é possível tratar dos efeitos benéficos para o indivíduo compassivo.

\footnotetext{
${ }^{2} \mathrm{~A}$ Mulher-Maravilha se rende e é imediatamente castigada. Mulher-Maravilha: "Esses guardas marcianos não me
} reconheceram ou me amarrariam mais forte!”, in: WONDER WOMAN n 2, out. 1942 apud LEPORE (2017, p. 290). 
A vida envolve sempre a dor, contudo a compaixão dá a possibilidade de continuar (CAMPBELL, 1990). A compaixão desenvolve em quem a sente um bem-estar ao longo do tempo. Com relação ao grupo a compaixão desperta entre os membros uma atitude de proximidade fraterna, respeito e disponibilidade à ajuda. Tomando a história da Mulher-Maravilha e os efeitos da compaixão sobre quem a pratica, Busch e Scarlet (2018) observam que:

Embora a Mulher-Maravilha tenha força física e longevidade superiores, é o senso de compaixão da super-heroína que parece gerar força e resiliência. $\mathrm{Na}$ verdade, alguns estudos sugerem que a compaixão conduz à maior resiliência fisiológica e psicológica, bem como à maior longevidade (BUSCH; SCARLET, 2018, p. 135).

A compaixão pode ser desmembrada nas seguintes características: empatia, desejo de ajudar e atitude altruísta, aspectos encontrados na cena narrada abaixo. "Por exemplo, quando se aproxima de uma garotinha que foi excluída de um jogo de espada pelo simples fato de ser mulher, a Mulher-Maravilha vê sua dor, identifica-se com a garota e ensina-a como lutar com a espada e sair-se melhor do que os garotos” (BUSCH; SCARLET, 2018, p. 136).

Semelhante situação de consolar uma garota injustiçada quando ${ }^{3}$ dá apoio a uma garota que é excluída de um jogo com meninos por ser menina.

Em outra situação, a Mulher-Maravilha é empática e demonstra desejo de ajudar os outros que não conhece quando disputa com as amazonas em um concurso pelo direito de sair da ilha e auxiliar as pessoas do mundo dos homens. Um exemplo muito relevante do impacto da compaixão sobre a vida do praticante é experienciado por Diana, conforme expressam Busch e Scarlet (2018, p. 137):

Durante uma luta contra a medusa, a Mulher-Maravilha sacrifica a própria visão para salvar uma criança pequena. Toda a vez que a deusa Atena lhe oferece uma benção, ela escolhe ajudar o próximo em vez de voltar a enxergar; a atitude compassiva da superheroína torna a cegueira mais suportável. A abnegação e compaixão incessantes da Mulher-Maravilha não só levam Atena a devolver a visão para a filha de Hipólita como a conceder à super-heroína o poder de alcance da visão da deusa. Com isso, Atena compartilha também sua sabedoria com a Mulher-Maravilha (BUSCH; SCARLET, 2018, p. 137).

Talvez nem tanto nas batalhas, mas certamente na sua vida como Diana Prince, a amazona demonstra outra virtude: temperança. Essa virtude é descrita por Comte-Sponville (2009) como a moderação nos desejos sensuais e a garantia de um desfrutar mais puro e pleno. Para o autor: "A

\footnotetext{
${ }^{3}$ Mulher-Maravilha: "Não dê bola, Olive. Na próxima você vai se sair melhor." Olive: "Eu sou tão boa quanto aqueles meninos malvadões!", in: Sensation Comics, n 58, outubro de 1946 apud LEPORE (2017, p. 316).
} 
temperança é essa moderação pela qual permanecemos senhores de nossos prazeres, em vez de seus escravos" (p.46). Como todo super-herói, a Mulher-Maravilha é senhora sobre seus desejos para poder minimizar o que quer para si para ir buscar o melhor para o outro. Comte-Sponville (2009, p. 46) complementa que: "O intemperante é um escravo, mais subjugado ainda por transportar em toda parte seu amo consigo. Prisioneiro de seu corpo, prisioneiro de seus desejos ou de seus hábitos, prisioneiro de sua força ou de sua fraqueza."

A temperança visa respeitar os nossos limites, pois é a prudência aplicada aos prazeres estabelecendo prazer em não precisar de nada. A temperança atinge e visa dominar os desejos mais necessários à vida e, portanto, os mais difíceis de fazê-lo. (COMTE-SPONVILLE, 2009). A temperança é narrada tanto nas amazonas em Themyscera quanto em Diana no mundo dos homens. Sobre o costume das amazonas, Langley (2018b) informa que: “[...] elas dedicam todo o espaço da ilha da reforma [?] para ajudar os infratores a se tornarem pessoas melhores, em vez de puni-los.” A mesma atitude é observada na Mulher-Maravilha, que auxilia seus inimigos a se regenerarem, testemunha a favor deles no tribunal e protege quem já tentou matá-la.

Como todo super-herói que se preze, a Mulher-Maravilha é símbolo de coragem. Essa é taxada por Comte-Sponville (2009, p. 51) como a virtude mais universalmente valorizada e: "[...] a virtude dos heróis; e quem não admira os heróis?” A relação da heroína com a coragem pode ser explicitada em palavras: "[...] a coragem só é verdadeiramente estimável do ponto de vista moral quando se põe, ao menos em parte, a serviço de outrem, quando escapa, pouco ou muito, do interesse egoísta imediato” (p. 54); é o que ocorre em uma história de manifestação ${ }^{4}$ em que lutava pelos direitos de alimentação das crianças americanas.

Sobre a íntima relação da coragem com o medo, Comte-Sponville (2009, p. 55) declara que: “[...] a coragem é, sobretudo, uma fraca sensibilidade ao medo, seja por ele ser pouco sentido, seja por ser bem suportado, ou até com prazer." O prazer em suportar o medo não estaria na própria ação em si, mas no resultado almejado, no valor da ação, porque muitas pessoas podem se colocar em situações de medo apenas pelo prazer de superá-lo sem benefício algum para outrem, enquanto a pessoa virtuosa só enfrenta o medo para vantagem de alguém. O virtuoso supera o medo por vontade mais forte e generosa. Quando a Mulher-Maravilha precisa se disfarçar de Diana Prince, uma mera humana, ela questiona sua própria identidade diante de não ter um lugar preciso entre os humanos que tanto ajuda, ora amada ora desprezada, mas não tem dúvidas quanto a arriscar seu disfarce e enfrentar a possibilidade de morte para salvar suas meio-irmãs semi-deusas, como na história em quadrinhos de Wonder Woman (2006).

\footnotetext{
${ }^{4}$ A Mulher-Maravilha lidera uma gigante manifestação contra a algazarra do leite. A Companhia Internacional do Leite está matando de fome as crianças da América, in: Sensation Comic n 7, jul. 1942 apud LEPORE (2017, p. 263).
} 
Coragem é um atributo de todos os super-heróis, aliás, é o que os qualifica como tais. Com a Mulher-Maravilha a bravura está nas lutas contra seus inimigos mortais e imortais e também no modo de vida que leva ao se engajar na política, para que sua vida sirva de exemplo, sendo alvo de inúmeras críticas em quase todas as suas atitudes (WOOD, 2018b). Contudo, continua a combater o mal e a injustiça mesmo diante de várias provações e dúvidas externas quanto ao seu caráter, portanto, ela se expõe também aos ataques morais, sem se proteger deles, para agir conforme a sua moral.

Na provável relação entre heroísmo e coragem, Comte-Sponville (2009, p. 64) afirma: “[...] o verdadeiro herói será aquele que for capaz de enfrentar não apenas o risco, que risco sempre há, mas, se preciso, a certeza da morte ou, mesmo, pode acontecer, da derrota final." Apesar de ser a virtude dos heróis, convém lembrar que a coragem pode ser usada para o bem ou para o mal, sendo característica dos heróis quando se junta à compaixão e à generosidade.

A generosidade, por sua vez, consiste em encontrar prazer em servir o outro, descobrir o seu bem-estar na ação em benefício de outrem. Essa virtude se relaciona ao temperamento de quem a executa por ter um caráter mais afetivo e espontâneo. $\mathrm{O}$ agir generoso se dá pelas exigências do amor, da moral e da solidariedade; tal ato é aquele que vai muito além das pessoas a quem se ama, envolve uma espécie de amor mais geral e amplo pela humanidade. É generoso quem consagra energia a uma felicidade que não é a sua nem de seus íntimos (COMTE-SPONVILLE, 2009). A benevolência da heroína se mostra em episódio com a criatura mitológica que encontra ao agir para preservar a humanidade de um ataque mágico da feiticeira Morgana. Morgana ameaçou transformar humanos em monstros caso a princesa não roubasse uma espada para ela, dentro da caverna de Merlin. Lá a amazona venceu um dragão que protegia a espada. Quando ela retirou a espada, ele começou a chorar, a amazona o consola explicando sua missão. A criatura elaborou um plano que ajudaria os dois, pois ele sabia como tirar os poderes da espada. Com a ajuda do dragão, angariada após ela demonstrar benevolência, derrotou a vilã, devolveu a espada para o guardião, fazendo um novo amigo (WONDER WOMAN, 2018). Nas primeiras histórias da heroína, em 1941, a princesa amazona encontra o piloto Steve Trevor acidentado em sua ilha, ajudando-o ainda desacordado ${ }^{5}$.

O efeito da benevolência para o próprio indivíduo está na "Consciência e confiança, pois: consciência de ser livre, confiança no uso que se fará disso. É por isso que a generosidade produz autoestima” (COMTE-SPONVILLE, 2009, p. 105). A pessoa altruísta está mais livre de seus afetos. Aproveitando as palavras do mesmo autor: "Ser generoso é ser livre de si, de suas pequenas covardias, de suas pequenas posses, de suas pequenas cóleras, de seus pequenos ciúmes...” (COMTE-SPONVILLE, 2009, p. 106). O generoso consegue dar sem amar, fato socialmente desejável, pois não se consegue amar

\footnotetext{
${ }^{5}$ Amazona: “Isto é... Isto é...” ,Mulher-Maravilha: “Um homem! Um homem na ilha Paraíso! Depressa! Temos que levá-lo ao hospital”, in: All Star Comics nº dez. 1941- jan 1942, apud LEPORE (2017, p. 32).
} 
a todos, mas se pode ser generoso com muitos. Em resumo, a moral da complacência conduz à ética do amor, pois se o amor entre todos de uma comunidade é o objetivo, a generosidade é o caminho (COMTE-SPONVILLE, 2009). Em um mundo em que há mais casos diários de egoísmo, a MulherMaravilha atesta o valor da generosidade aliando-a com a coragem, demonstrando seu heroísmo generoso enquanto precisa escolher entre salvar um ônibus cheio de pessoas indefesas e seus amigos agentes de defesa em um helicóptero, ela preza por auxiliar aqueles que não podem se salvar sozinhos. (WONDER WOMAN, 2009, n 32).

Houve momentos em que o heroísmo da Mulher-Maravilha teve de ser discreto depois de ela matar seu arqui-inimigo Maxwell Lord em frente às câmeras da televisão. Ela precisa então mudar de identidade, deixando de ser a Diana de Themyscera e a Mulher-Maravilha. Com a ajuda de Batman, consegue uma nova identidade como Diana Prince, agente do departamento de meta-humanos, para que continue ajudando as pessoas (WONDER WOMAN, 2006). Tal situação remete à virtude da humildade, assim como no enredo em que salva um bebê $\hat{e}^{6}$ em um prédio em chamas, não respondendo aos repórteres que desejam saber quem ela é.

A humildade é uma virtude sempre insatisfeita consigo mesma, de acordo com Comte-Sponville (2009). Essa insatisfação é constante nas palavras da heroína, que sempre vê sua entrega à humanidade menor do que poderia ter sido. A humildade duvida de tudo, mas é capaz de levar à elevação, pois orienta a buscar fazer sempre o melhor, sem orgulho e ostentação.

Quando a Mulher-Maravilha sai de sua ilha junto às amazonas e descobre o mundo dos homens, tem oportunidade de viver experiências em uma civilização que nem sempre reconhece seu valor como guerreira guiada pelo ideal de justiça. Mesmo diante de grandes diversidades ela supera a desesperança e age com força interior para se manter dentro da ética que aprendeu ser mais importante que elogios e vantagens pessoais. As histórias em quadrinhos da princesa amazona, desde 1942 até a atualidade, mostram bem mais que uma super-heroína forte e destemida, o engrandecimento de modos de viver enfatizando o coletivo.

As HQs surgiram de modo complementar nos jornais de papel, atrelando imagem e texto na divulgação de notícias. Com a popularização das histórias em quadrinhos e seu uso político na $2^{a}$ Guerra Mundial o alcance das narrativas dos heróis se expande. A chegada de uma heroína poderosa aos quadrinhos dava exemplo de que mulheres poderiam exercer funções de destaque na sociedade. Como ícone da chamada segunda onda do feminismo, a Mulher-Maravilha inspirou e ainda inspira as mulheres a ocuparem de modo seguro os espaços públicos.

As histórias da princesa amazona não se limitaram a servir de modelo apenas para as meninas e mulheres de várias gerações, pois muito do que fez nos quadrinhos são valores tidos como universais. As

\footnotetext{
${ }^{6}$ Como pode ser visto na imagem de um salvamento anônimo, in: King Feature Syndicate 1944 apud Greenberger (2017).
} 
lições da amazona demonstram os efeitos para o indivíduo e para o coletivo das práticas de virtudes como a justiça ao buscar amparar os desvalidos; a compaixão pelos seus inimigos mais sanguinários; o conhecimento sobre as feras da mitologia antiga; a sabedoria na utilização de seu autoconhecimento; a temperança em sua vida pessoal equilibrada; a coragem em combate como todo super-herói e em encabeçar lutas pelos direitos sociais; a generosidade em pequenos atos cotidianos com pessoas comuns diante de dores da vida, e a humildade ao continuar trabalhando pela humanidade disfarçada, sem poder assumir seu papel de Mulher-Maravilha. Como apontado, muitas virtudes são estampadas nos atos da heroína, servindo de modelo de valores difíceis de serem colocados em prática, mas que tornam a vida muito mais significativa. 


\section{REFERÊNCIAS}

ALVES, J. M. Histórias em quadrinhos e educação infantil. Psicol. cienc. prof., Brasília , v. 21, n. 3, p. 2-9, set. 2001. Disponível em: http://www.scielo.br/scielo.php?script=sci_arttext\&pid=S141498932001000300002\&lng=en\&nrm=iso. Acesso em 29 jul. 2020. BALLMANN, F. A nona arte: história, estética e linguagem de quadrinhos. Dissertação (Mestrado em Ciências da Linguagem). Universidade do Sul de Santa Catarina, Tubarão, 2009.

BUSCH, J.; SCARLET, J. A compaixão é meu superpoder. In: LANGLEY, Travis; WOOD, Mara (eds.). A psicologia da Mulher-Maravilha: descubra as virtudes da maior super-heroína que conhecemos e porque ela deve ser a grande inspiração para toda a humanidade. Tradução Amanda Moura. São Paulo: Única, 2018. p. 135-140.

CAMPBELL, J. O poder do mito. Tradução Carlos Felipe Moisés. São Paulo: Palas Athena, 1990.

CARVAlHO, D. A educação está no gibi. Campinas, São Paulo: Papirus, 2006.

CARUSO, F.; SILVEIRA, C. Quadrinhos para a cidadania. História, Ciências, Saúde - Manguinhos, Rio de Janeiro, v.16, n.1, , p.217-236, jan./mar. 2009.

COELHO, N. N. Panorama histórico da literatura infanto-juvenil: das origens indoeuropéias ao Brasil contemporâneo. 3 ed. São Paulo: Quíron, 1985.

CONTE-SPONVILLE, A. Pequeno tratado das grandes virtudes. Tradução Eduardo Brandão. 2 ed. São Paulo: Editora WMF Martins Fontes, 2009.

DUMONT, L. M. M.; RAMOS, R. B. T. A leitura de histórias em quadrinhos da Marvel e da DC Comics e a etnometodologia: relevância e desdobramentos. Perspect. ciênc. inf., Belo Horizonte, v. 23, n. 3, p. 188-205, set. 2018. Disponível em: http://www.scielo.br/scielo.php?script=sci_arttext\&pid=S141399362018000300188\&lng=en\&nrm=iso. Acesso em 25 jul. 2020.

EISNER, W. Narrativas gráficas de Will Eisner. Tradução Leandro L. Del Manto. São Paulo: Devir, 2005.

GREENBERGER, R. Mulher-Maravilha: amazona. heroína. ícone. Tradução Dandara Palankof. Rio de Janeiro: Leya, 2017.

JAEGER, W. W. Paidéia: a formação do homem grego. Tradução Artur M. Parreira. 4 ed. São Paulo: Martins Fontes, 2001. 
KNOWLES, C. Nossos deuses são super-heróis: a história secreta dos super-heróis das histórias em quadrinhos. São Paulo: Cultrix, 2008.

LANGLEY, T. Arquivos da virtude I: justiça. In: LANGLEY, Travis; WOOD, Mara (eds.). A psicologia da Mulher-Maravilha: descubra as virtudes da maior super-heroína que conhecemos e porque ela deve ser a grande inspiração para toda a humanidade. Tradução Amanda Moura. São Paulo: Única, 2018a. p. 71-73.

LANGLEY, T. Arquivos da virtude III: temperança. In: LANGLEY, Travis; WOOD, Mara (eds.). A psicologia da Mulher-Maravilha: descubra as virtudes da maior super-heroína que conhecemos e porque ela deve ser a grande inspiração para toda a humanidade. Tradução Amanda Moura. São Paulo: Única, 2018b. p. 151-155

LEPORE, J. A história secreta da Mulher-Maravilha. Rio de Janeiro: Best Seller, 2017.

MARNY, J. Introdução à sociologia das histórias em quadrinhos. Lisboa: Horizonte, 1970.

POSTEMA, B. Estrutura narrativa nos quadrinhos: construindo sentido a partir de fragmentos. São Paulo: Peirópolis, 2018.

XAVIER, C. L. M. Quadrinhos, psicologia e espiritualidade: símbolos e mitos estruturam o desenvolvimento psíquico e espiritual. Psicol. Am. Lat., México, n. 4, ago. 2005. Disponível em: http://pepsic.bvsalud.org/scielo.php?script=sci_arttext\&pid=S1870-

350X2005000200008\&lng=pt\&nrm=iso. Acesso em: 25 jul. 2020.

VIANA, N. Heróis e super-heróis no mundo dos quadrinhos. Rio de Janeiro: Achiamé, 2005.

WESCHENFELDER, G. V. Aspectos educativos das histórias em quadrinhos de super-heróis e sua importância na formação moral, na perspectiva da ética. (Dissertação de mestrado). Mestrado em Educação, Centro Universitário La Salle, Canoas, RS, 2011.

WESCHENFELDER, G. V.; FRADKIN, C.; YUNES, M. A. M. Super-heróis como recursos para promoção de resiliência em crianças e adolescentes. Psic.: Teor. e Pesq., Brasília, v. 33, e33425, 2017. Disponível em: http://www.scielo.br/scielo.php?script=sci_arttext\&pid=S010237722017000100423\&lng=en\&nrm=iso. Accesso em 26 jul. 2020.

WONDER WOMAN. New York, NY, EUA: DC Comics, n. 2, set. 2006.

WONDER WOMAN. New York, NY, EUA: DC Comics, n. 32, jul. 2009.

WONDER WOMAN. New York, NY, EUA: DC Comics, n. 33, ago. 2009. 
WONDER WOMAN. New York, NY, EUA: DC Comics, n. 6, jun. 2019.

WONDER WOMAN: as aventuras da super-heroína. São Paulo: Ciranda Cultural, 2018.

WOOD, M. Arquivos da virtude II: sabedoria e conhecimento. In: LANGLEY, Travis; WOOD, Mara (eds.). A psicologia da Mulher-Maravilha: descubra as virtudes da maior super-heroína que conhecemos e porque ela deve ser a grande inspiração para toda a humanidade. Tradução Amanda Moura. São Paulo: Única, 2018. p. 105-107.

WOOD, M. Arquivos da virtude IV: coragem. In. LANGLEY, Travis; WOOD, Mara (eds.). A psicologia da Mulher-Maravilha: descubra as virtudes da maior super-heroína que conhecemos e porque ela deve ser a grande inspiração para toda a humanidade. Tradução Amanda Moura. São Paulo: Única, 2018. p. 187-189. 